\title{
Cost of anaesthetic drugs and clinical budgeting
}

\author{
J R LETHBRIDGE，J SECKER WALKER
}

In 1980 Astley and Secker Walker calculated that the average total cost to the National Health Service of one anaesthetic was $£ 29 \cdot 98 .{ }^{1}$ The cost of drugs for the year $1979-80$ was $£ 44032$ or $8 \cdot 6 \%$ of the total hospital cost of anaesthesia of $£ 506459$. This paper examines the drugs bill for the University College Hospital group of hospitals between April 1984 and March 1985 and compares it directly with the study of the drugs bill for 1979-80. ${ }^{1}$ It highlights the financial consequences of changes in anaesthetic practice. We have also examined the cost of anaesthesia for one hour in 1985 and compared it with the cost of anaesthesia for the same operation (hysterectomy) lasting one hour in 1980. This shows how the choice of the newer anaesthetic drugs in 1985 led to a rise in costs, when compared with 1980, which is above the percentage rise of the Retail Price Index. Medical and nursing staff salaries account for $83 \%$ of the cost of anaesthesia, but the cost of anaesthetic drugs is the next most important factor. If the drugs bill were allowed to rise faster than the annual increase for inflation in the departmental budget it would be necessary to make equivalent economies elsewhere in the anaesthetic department's budget.

\section{Cost of drugs and equipment}

Tables I-III show the costs of various anaesthetic drugs and disposable equipment in 1980 and in 1985 . From 1980 to 1985 the Retail Price Index rose by $37 \%$, which means that $£ 1$ in 1980 was the equivalent of $£ 1.37$ in 1985 . We have divided all the 1985 prices and amounts by this factor of 1.37 in order to express all the 1985 pounds sterling in terms of 1980 pounds. It is now becoming the practice to increase budgets in line with inflation: as we have eliminated this factor in our tables any increases in amounts or prices are real increases that will not be met by increasing the budget only in line with increases in the Retail Price Index. While the caseload remained roughly equal for each of the two years under study, the total bill for anaesthetic drugs showed a real increase. The tables show that changing practice by anaesthetists, including the more frequent choice of more expensive drugs, is the most important factor in increasing drug costs.

Table I shows that the cost of enflurane remains much higher than that of halothane despite a halving of the price of enflurane in real terms. Enflurane is increasingly being used by anaesthetists, and this preference, which may largely be due to its more rapid elimination as well as the increased awareness of halothane hepatitis, has made an important contribution to the increased drugs bill. Though the real price of enflurane has fallen by a half, its use has now increased to such an extent that while in 1980 expenditure on enflurane accounted for only $28 \%$ of the money spent on volatile agents by 1985 it accounted for $60 \%$. There has been a corresponding decrease in the use of halothane.

While the costs of many of the older drugs have decreased in real terms, the cost of an ampoule of thiopentone $500 \mathrm{mg}$ with water has shown a real increase over the five year period. This period has seen the withdrawal of Althesin (alphaxolone-alphadolone acetate) and propanidid, while methohexitone and etomidate have not gained in

\section{Guy's Hospital, London SE1 9RT}

J R LETHBRIDGE, MB, FFARCS, senior registrar

University College Hospital, London WC1E 6AU

J SECKER WALKER, MB, FFARCS, consultant anaesthetist

Correspondence to: Dr J R Lethbridge, Department of Anaesthetics, Guy's Hospital, London SE1 9RT. popularity. By 1985 the use of thiopentone had increased to the point where it accounted for $95 \%$ of the total money spent on induction agents; the corresponding figure for 1980 was $76 \%$.

The new muscle relaxants atracurium and vecuronium are considerably more expensive than the older drugs such as pancuronium and tubocurarine, whose prices have decreased in real terms. Other new drugs that have been added to the armamentarium of anaesthetists, such as glycopyrronium and doxapram, have also made a contribution to the increased drugs bill.

We examined the costs of drugs and disposable equipment that are commonly used in anaesthesia for hysterectomy and compared them with those same costs as reported for 1980. Three important points emerge.

The cost of the disposable items commonly used by the anaesthetist during a hysterectomy have decreased.

The cost of the one hour anaesthetic using the older muscle relaxant pancuronium and the older volatile agent halothane has decreased in real terms.

When the newer drugs are used-vecuronium instead of pancuronium and enflurane instead of halothane-there is a substantial real increase in the drug component of the anaesthetic cost from $£ 2.99$ to $£ 5.09$. This is a real increase of $£ 2 \cdot 10$ or $70 \%$; it represents the price to be paid for using the newer anaesthetic drugs after making allowances for inflation.

\section{Discussion}

A previous report by Simpson in 1978 noted that despite inflation the cost of anaesthetic drugs had stayed fairly constant over the preceding year. ${ }^{2}$ Another report in 1978 , however, drew attention to the rising cost of disposable equipment. ${ }^{3}$ The present study seems to indicate that in the present competitive economic climate some of the commonly used disposable equipment is relatively cheaper than it was four years ago. (This may be a reflection of both reduced costs and reduced profit margins over this period.)

TABLE I-Some drug prices and amounts spent during financial years 1979-80 and $1984-5^{\star}$

\begin{tabular}{|c|c|c|c|c|}
\hline \multirow[b]{2}{*}{ Drug grouping } & \multicolumn{2}{|c|}{$1979-80$} & \multicolumn{2}{|c|}{$1984-5$} \\
\hline & $\begin{array}{l}\text { Price per } \\
\text { ampoule } \\
(£)\end{array}$ & $\begin{array}{c}\text { Cost for } \\
\text { year } \\
(\mathfrak{E})\end{array}$ & $\begin{array}{l}\text { Price per } \\
\text { ampoule } \\
(\mathfrak{E})\end{array}$ & $\begin{array}{l}\text { Cost for } \\
\text { year } \\
(\mathfrak{E})\end{array}$ \\
\hline \multicolumn{5}{|l|}{ Induction agents: } \\
\hline Thiopentone $500 \mathrm{mg}$ with water & 0.81 & 6523 & 0.97 & 12616 \\
\hline \multicolumn{5}{|l|}{ Muscle relaxants: } \\
\hline Suxamethonium & 0.39 & 3219 & 0.25 & 2772 \\
\hline Tubocurarine & 0.75 & 3803 & 0.57 & 1140 \\
\hline Pancuronium & 0.70 & 2272 & 0.54 & 1391 \\
\hline Vecuronium 4 mg & & & 1.00 & 2175 \\
\hline Atracurium $2.5 \mathrm{ml}$ & & & 0.97 & 1261 \\
\hline Atracurium $5.0 \mathrm{ml}$ & & & $1 \cdot 88$ & 908 \\
\hline \multicolumn{5}{|l|}{ Volatile agents: } \\
\hline Halothane & $6 \cdot 42$ & 4945 & $5 \cdot 27$ & 4851 \\
\hline Enflurane & $28 \cdot 75$ & 2092 & $14 \cdot 27$ & 7928 \\
\hline \multicolumn{5}{|l|}{ Other agents: } \\
\hline Atropine & 0.04 & 561 & 0.04 & 591 \\
\hline Glycopyrronium & & & 0.74 & 840 \\
\hline Doxapram & & & $1 \cdot 32$ & 1462 \\
\hline Fentanyl $0.1 \mathrm{mg} / 2 \mathrm{ml}$ & 0.45 & 1616 & 0.34 & 1808 \\
\hline Fentanyl $0.5 \mathrm{mg} / 10 \mathrm{ml}$ & & & 1.57 & 1961 \\
\hline Papaveretum +hyoscine & 0.07 & 545 & 0.07 & 770 \\
\hline Nitrous oxide ( $\mathrm{G}$ size $)$ & $12 \cdot 20$ & 8232 & $10 \cdot 93$ & 7311 \\
\hline Total: all anaesthetic drugs & & 44032 & & 58451 \\
\hline
\end{tabular}

$\star(i)$ The price per ampoule and cost for year are in pounds sterling and include VAT. (ii) All the amounts shown have been expressed in 1980 pounds to eliminate the effects of inflation. 
The new drugs such as enflurane and vecuronium, however, tend to be more expensive than the older drugs with which they are competing. Furthermore, the introduction of the new muscle relaxants vecuronium and atracurium may be encouraging anaesthetists to ventilate patients who previously were being allowed to breathe spontaneously. The shorter duration of action of these newer muscle relaxants may allow anaesthetists to ventilate patients for short procedures when previously this was less practicable. Although the price of enflurane has come down since 1980 , it remains nearly three times the cost of halothane, the drug that it commonly replaces, and it is six times the cost for one MAC hour. ${ }^{\star}$

The present government insists that district health authorities remain within their cash limits, and similar rules will apply to departmental budgets. Clinical budgeting in the anaesthetic department ${ }^{4}$ was described before the Griffiths management changes. ${ }^{5}$ The inquiry insisted that clinical budgets should be introduced more widely as a means of maintaining tighter financial control and responsibility. A review of clinical budgeting and costing experiments noted how clinical costing did not usually, in itself, encourage clinicians to change their pattern of expenditure, ${ }^{6}$ but the same review reported a more encouraging picture emerging from clinical budgeting, with the active participation of clinicians trying to keep within agreed expenditure plans.

The effect of changes in anaesthetic practice brought about partly by the introduction of new drugs may be compounding the effect of the increased costs of the drugs themselves. The increased use of more expensive drugs is a factor that may lead to problems in departmental budgeting, as it will become necessary to make corresponding savings elsewhere in the departmental budget. The need to search elsewhere within the budget to balance the overspending on pharmacy will inevitably lead the budget holder to consult among his colleagues with questions, perhaps uncomfortable, about costs of anaesthetic equipment, costs of various anaesthetic techniques, maintenance costs, study leave, staffing levels, and so on. If the budget holder and his colleagues are certain that no further savings can be made within the department then it will be necessary to approach the unit manager for additional funding. It will be necessary to defend the need to use new drugs that cost more than the Department of Health and Social Security has allowed for inflation. It is possible that additional funds could be provided only by making savings in other specialty budgets, and this could give rise to discussions, for example, about the relative benefit to patients of expensive staple guns for anastomoses versus newer relaxant drugs. If there is a failure to make this case in many districts faced with the same financial problems this could seriously inhibit the development of new techniques in anaesthesia.

As computer terminals are installed in operating theatre offices, as doubtless they will be, there will be easier access to measurements of anaesthetic caseload against which the pharmacy bill will have to be balanced. The University College Hospital anaesthetic department's budget does not include the cost of drugs at present, but there are plans for this to be changed once computers are able to collect all the necessary data. ${ }^{4}$ In this way a form of medical audit is bound to begin. It is probably better that clinicians undertake this audit themselves rather than have it imposed on them by the new management structure.

The data presented here have shown those factors that are tending to increase the drugs bill faster than the rate of rise of the Retail Price Index. These factors include the changing practices of anaesthetists and the increasing use of new and nore expensive drugs, which are steadily replacing some of the older favourites. A recent editorial in the $B M \mathcal{F}$ noted that in the United States halothane has almost completely been supplanted by enflurane and isoflurane and made the point that health authorities should pay for the more expensive agent rather than have to join the medical insurers in paying large

${ }^{\star}$ Minimum alveolar concentration (MAC). This refers to the alveolar concentration at which half the subjects will not respond to a surgical stimulus. Because enflurane has a MAC of $1 \cdot 7 \%$ and halothane has a MAC of $0.7 \%$ more enflurane than halothane is used when the drugs are used in equivalent concentrations. This leads to enflurane costing six times as much as halothane when used to produce anaesthesia of equivalent depth.
TABLE II-Cost of general anaesthetic for hysterectomy lasting one hour ${ }^{\star}$

\begin{tabular}{|c|c|c|c|}
\hline & $\begin{array}{c}1980 \\
\text { Using } \\
\text { older } \\
\text { drugs } \\
(\mathfrak{£})\end{array}$ & $\begin{array}{c}1985 \\
\text { Using } \\
\text { older } \\
\text { drugs } \\
(£)\end{array}$ & $\begin{array}{c}1985 \\
\text { Using } \\
\text { newer } \\
\text { drugs } \\
(£)\end{array}$ \\
\hline Disposables & $3 \cdot 20$ & $2 \cdot 24$ & $2 \cdot 24$ \\
\hline Thiopentone & $0 \cdot 81$ & 0.97 & 0.97 \\
\hline Pancuronium & $1 \cdot 40$ & $1 \cdot 08$ & Vecuronium $£ 2.00$ for $8 \mathrm{mg}$ \\
\hline Nitrous oxide & $0 \cdot 30$ & $0 \cdot 30$ & $0 \cdot 30$ \\
\hline Oxygen & 0.04 & 0.03 & 0.03 \\
\hline Halothane (1 MAC hour) & $0 \cdot 30$ & $0 \cdot 24$ & $\begin{array}{c}\text { Enflurane } £ 1.65 \\
(1 \mathrm{MAC} \text { hour })\end{array}$ \\
\hline Atropine & 0.08 & 0.08 & 0.08 \\
\hline Neostigmine & 0.06 & 0.06 & 0.06 \\
\hline $\begin{array}{l}\text { Total for drugs } \\
\text { Total for drugs and disposable equipment }\end{array}$ & $\begin{array}{l}2 \cdot 99 \\
6 \cdot 19\end{array}$ & $\begin{array}{l}2 \cdot 76 \\
5.00\end{array}$ & $\begin{array}{l}5 \cdot 09 \\
7 \cdot 33\end{array}$ \\
\hline
\end{tabular}

^All the amounts shown have been expressed in 1980 pounds to eliminate the effects of inflation.

TABLE III-Cost of disposable equipment for anaesthetic for hysterectomy ${ }^{\star}$

\begin{tabular}{lcc}
\hline & $\begin{array}{c}1980 \\
(\mathfrak{\Sigma})\end{array}$ & $\begin{array}{c}1985 \\
(£)\end{array}$ \\
\hline 3 Electrocardiography electrodes & 0.66 & 0.26 \\
Butterfly needle 23 gauge & 0.27 & 0.14 \\
Syringes and needles & 0.24 & 0.18 \\
Angiocath 16 gauge & 0.38 & 0.34 \\
Drip giving set & 0.65 & 0.75 \\
Hartmann's solution (1 litre) & 0.99 & 0.56 \\
Sticking plaster & 0.01 & 0.01 \\
\hline \multicolumn{1}{c}{ Total cost of disposables } & 3.20 & 2.24 \\
\end{tabular}

^All the amounts shown have been expressed in 1980 pounds to eliminate the effects of inflation.

settlements for avoidable halothane hepatitis. ${ }^{7}$ Although the data presented here show that the higher cost of newer drugs is one of the main factors in the increasing drugs bill, with many of the older drugs becoming relatively cheaper, there is one notable exception. Since the collection of the data for this paper the cost of thiopentone $500 \mathrm{mg}$ with water has risen from $£ 1 \cdot 33$ (including VAT) in July 1985 to $£ 1.66$ in May 1986 . This is a price rise of $22.5 \%$ during a period when the Retail Price Index rose by less than $5 \%$. As this study shows that thiopentone is a major component of the total drugs bill it is easy to see how a large increase in price of such an important item could have serious sequelae elsewhere within the anaesthetic department's budget. Both the increased use of this well established drug and its increasing price could be because there are now fewer competing induction agents than there were in 1980 . We have contacted the makers of thiopentone, who tell us that the rise in price is related to substantial increases in manufacturing costs as the manufacture of thiopentone is a complicated and labour intensive process.

The present study illustrates that in the context of clinical budgeting a budget for anaesthetic drugs, uplifted annually for inflation and sensitive to changes in workload, would nevertheless have caused serious problems for the budget holder.

We should like to thank Miss J Jones and her colleagues in the University College Hospital pharmacy for their help in collecting the data for this study.

\footnotetext{
References

1 Astley BA, Walker JS. Cost of anaesthesia. Br Med f 1982;285:189-91.

2 Simpson PM. The cost of anaesthetic drugs and equipment. Anaesthesia 1978;33:53-9.

3 Bailey PW. Pricing of anaesthetic techniques. Anaesthesia 1978;33:235-41.

Walker JS. A year's experience of functional budgeting in a clinical department. Anaesthesic 1980;35:316-8.

5 NHS Management Inquiry. Report. London: DHSS, 1983. (Griffiths report.)

6 Wickings I, Coles JM, Flux R, Howard L. Review of clinical budgeting and costing experiments. BrMed f 1983;286:575-8.

7 Blogg CE. Halothane and the liver: the problem revisited and made obsolete. $\mathrm{Br}$ Med $\mathrm{f}$ 1986;292:1691-2.

(Accepted 28 October 1986)
} 